\title{
The PATE gene is expressed in the accessory tissues of the human male genital tract and encodes a secreted sperm-associated protein
}

Ángel A Soler-García, Rangan Maitra, Vasantha Kumar, Tomoko Ise, Satoshi Nagata, Richard Beers, Tapan K Bera and Ira Pastan

\author{
Laboratory of Molecular Biology, Center for Cancer Research, National Cancer Institute, National Institutes \\ of Health, Bethesda, Maryland 20892-4264, USA
}

Correspondence should be addressed to I Pastan; Email: pastani@mail.nih.gov

Ángel A Soler-García is now at Center for Genetic Medicine Research, Division of Nephrology, Children's Research Institute, Children's National Medical Center, 3.5 Floor, Room R165, 111 Michigan Ave., NW, Washington DC 20010, USA

Rangan Maitra is now at Paradigm Genetics, Inc., 108 T W Alexander Drive, Research Triangle Park, North Carolina 27709, USA

\begin{abstract}
The PATE gene is expressed in prostate and testis. To determine if PATE is expressed in other accessory tissues of the male genital tract, RT-PCR of the epididymis and seminal vesicle was performed. PATE mRNA was highly expressed in the epididymis and seminal vesicle. In situ hybridization of the testis showed PATE mRNA is strongly expressed in the spermatogonia. The PATE gene encodes a 14-kDa protein with a predicted signal sequence and a cleavage site between residues G21 and S22. To determine if PATE is a secreted protein, 293T cells were transfected with a pcDNA-PATE-myc-His plasmid and protein immunoprecipitated with anti-myc monoclonal antibody. Western blot analysis showed the presence of PATE-myc-His protein was in the medium and the cell lysate. Confocal microscopy demonstrated that PATE-myc-His protein is found in the endoplasmic reticulum. The polyclonal antibody SOL-1 was generated by immunization of rabbits with recombinant PATE protein expressed and purified from Escherichia coli. Western blots were performed on extracts of prostate, testis, seminal vesicle and ejaculated spermatozoa, but PATE protein was only detected in the spermatozoa. Immunostaining of sperm smears revealed that PATE is located in a band-like pattern in the sperm head. Our data indicate that PATE is made by various sexual accessory tissues and secreted into the semen where it becomes associated with sperm, suggesting that PATE is a novel sperm-associated protein with a possible role in mammalian sperm maturation.

Reproduction (2005) 129 515-524
\end{abstract}

\section{Introduction}

Mammalian sperm are terminally differentiated cells. Their differentiation from round spermatids to highly polarized and fully motile cells is characterized by extensive biochemical, physiological and morphological events (Toshimori 1998, Ducheux et al. 2003). These events start in the testis in the process called spermiogenesis. For the sperm, extensive post-gonadal differentiation to maturity is required for successful fertilization. This post-gonad differentiation occurs in the male accessory glands such as the epididymis. These accessory glands contribute to the sperm maturation process by secreting factors into the seminal plasma, a complex biological fluid formed from the mix of various secretions in the male genital tract (Luo et al. 2001).

The epididymis provides a luminal environment that promotes both maturation and survival of the spermatozoa
(Hinton \& Palladino 1995, Hinton et al. 1996). In this luminal environment there are factors involved in glutathione conjugation and metabolism (Robaire \& Viger 1995, Hinton et al. 1996), inhibitors of complementmediated lysis (Griswold et al. 1986, Collard \& Griswold 1987, Sylvester et al. 1991) and protease inhibitors (Cornwall et al. 1992, Kirchhoff et al. 1998). The sperm become functionally mature while traveling through the epididymis duct gaining fertilization ability and zone recognition (Orgebin-Crist 1969, Bedford 1975). In hamsters, it has been proposed that the epididymis possesses a sperm sorting mechanism which discriminates viable from nonviable sperm (NagDas et al. 2000).

Seminal vesicle secretions constitute the major portion of the seminal plasma contributing factors that affect sperm motility. The contribution of the seminal vesicle secretions to sperm motility has been investigated using 
semen of several different mammals such as boar (Iwamoto et al. 1992, Jeng et al. 1993, Nichol et al. 1997), bull (Al-Somai et al. 1994), mouse (Peitz 1988) and human (Robert \& Gagnon 1996). In mice, the removal of the seminal vesicle greatly reduces mouse sperm fertility (Pang et al. 1979, Peitz \& Olds-Clarke 1986). Because the process by which mammalian sperm develops and matures to fully functional cells is not completely understood, the identification and characterization of new factors related to the process is important. In the following study we report the identification and characterization of PATE, a gene expressed in prostate and testis as a novel sperm-associated protein that may be involved in sperm maturation.

\section{Materials and Methods \\ Reverse transcription-PCR (RT-PCR) analysis}

Total RNA from epididymis and seminal vesicle was extracted using the Absolutely RNA RT-PCR Miniprep kit following instructions of the manufacturer (Stratagene, La Jolla, CA, USA). Total RNA from prostate and testis was obtained by BD Biosciences Clontech (Palo Alto, CA, USA). Single-stranded cDNA from RNA samples of each tissue was synthesized from $5 \mu \mathrm{g}$ total RNA using the Firststrand CDNA Synthesis kit (Amersham Biosciences; Piscataway, NJ, USA) following instructions from the manufacturer. PATE PCR amplification was performed using $1.5 \mu \mathrm{l}$ of the first-strand reaction and PATE specific primers PATE-12 sense (5'-ACAAGTCCCTCTTGCTGGAACTC-3') and PATE-363 antisense (5'-AAGGTCTTCATTGCACAGGTCATG-3') using the Hot Star Taq Master mix (Qiagen, Alameda, CA, USA). The thermocycling protocol was initial denaturation at $95^{\circ} \mathrm{C}$ for $15 \mathrm{~min}, 35$ cycles of denaturation at $94^{\circ} \mathrm{C}$ for $1 \mathrm{~min}$, annealing at $60^{\circ} \mathrm{C}$ for $1 \mathrm{~min}$, and elongation at $72{ }^{\circ} \mathrm{C}$ for $1 \mathrm{~min}$. This set of primers generates a $351 \mathrm{bp}$ fragment. For RNA control, PCR was performed using commercially available actin primers that generate a $640 \mathrm{bp}$ PCR fragment. The PCR products were analyzed on $1.0 \% 0.5 \times$ TAE $(20 \mathrm{mM}$ Tris, $10 \mathrm{M}$ acetate, $1 \mathrm{mM}$ EDTA; $\mathrm{pH}$ 8.0) agarose gel followed by ethidium bromide staining.

\section{In situ hybridization}

In situ hybridization of PATE mRNA on testis tissues was performed as described earlier (Kumar \& Collins 1994, Olsson et al. 2001). Biotinylated probes were prepared using cDNAs encoding PATE (1500 bp), the small nuclear RNA U6 (250 bp) and the B cell differentiation antigen CD22 (2068 bp) cloned in the pBluescript II SK(+) plasmid, using the BioNick Labeling System kit (Life Technologies, Gaithersburg, MD, USA) according to the manufacturer's instructions. Slides were hybridized using the In situ Hybridization and Detection System (Life Technologies) according to the manufacturer's instructions. The slides were counterstained using $0.2 \%$ Light Green stain, rinsed through a series of alcohol grades, and mounted in Cytoseal (Stephens Scientific, Riverdale, NJ, USA). Microscopic evaluation was performed using a Nikon Eclipse 800 microscope.

\section{Cell culture and transfection}

293T cells (American Type Culture Collection, Manassas, VA, USA) were grown in a $5 \% \mathrm{CO}_{2} / 95 \%$ air humidified incubator at $37^{\circ} \mathrm{C}$ and in D-MEM (Quality Biological Inc., Gaithersburg, MD, USA) supplemented with $10 \%$ FBS, $2 \mathrm{mM}$ L-glutamine, $100 \mathrm{units} / \mathrm{ml}$ penicillin, and $100 \mu \mathrm{g} / \mathrm{ml}$ streptomycin. Plasmid DNA transfection of 293T cells was performed with Lipofectamine 2000 (Invitrogen, Carlsbad, CA, USA) according to the manufacturer's instructions. Assays were performed $48 \mathrm{~h}$ after transfection.

\section{Detection of secreted PATE}

293T cells were transfected with pcDNA3-PATE-myc-His plasmid expressing PATE protein with a myc-His epitope tag at the carboxy terminus using Lipofectamine 2000 following the manufacturer's protocol (Invitrogen). Culture media and cells were collected by aspiration and trypsinization respectively. PATE-myc-His and actin proteins were immunoprecipitated with an anti-myc monoclonal antibody $(\mathrm{mAb})$ and an actin polyclonal antibody (pAb) (Santa Cruz Biotechnology, Inc., Santa Cruz, CA, USA) from the $5 \mathrm{ml}$ culture medium and $1 \mathrm{mg}$ total cell lysate respectively, following standard protocols (Harlow \& Lane 1999). One-fifth of the immunoprecipitated protein was loaded in $4-20 \%$ PAGE gel (BioRad, Hercules, CA, USA) and transferred to PVDF membranes. Membranes were immunoblotted with anti-myc or anti-actin mAbs (1:1000 dilution) followed by rat anti-mouse IgG1-horseradish peroxidase (HRP)-conjugated mAb (1:1000 dilution). Immunoblotted membranes were detected using an $\mathrm{ECL}$ detection kit (Amersham Biosciences).

\section{Subcellular localization of PATE}

For PATE subcellular localization, 293T cells were transfected with pcDNA PATE-myc-His. After $48 \mathrm{~h}$, cells were washed 3 times with PBS, fixed in $1 \mathrm{ml} 3.7 \%$ formaldehyde in PBS for $10 \mathrm{~min}$ at $25^{\circ} \mathrm{C}$ and washed 3 times for $10 \mathrm{~min}$ with PBS. Cells were permeabilized with $1 \mathrm{ml}$ $0.1 \%$ Triton X-100 in PBS for $5 \mathrm{~min}$ at $25^{\circ} \mathrm{C}$, washed and blocked with $5 \mu \mathrm{g} / \mathrm{ml}$ normal goat globulin (NGG) in PBS $+0.1 \%$ saponin for $20 \mathrm{~min}$ at $25^{\circ} \mathrm{C}$. Blocked cells were incubated with mouse anti-myc mAb (Molecular Probes, Inc., Eugene OR, USA), $5 \mu \mathrm{g} / \mathrm{ml}$ in PBS-NGGsaponin for $90 \mathrm{~min}$ at $25^{\circ} \mathrm{C}$ or overnight at $4{ }^{\circ} \mathrm{C}$. Coverslips were washed 3 times, incubated with goat anti-mouse Alexa Fluor 594 antibody $(5 \mu \mathrm{g} / \mathrm{ml})$ in PBS-NGG-saponin for $60 \mathrm{~min}$ at $25^{\circ} \mathrm{C}$ and washed 3 times with PBS (Molecular Probes, Inc.). To visualize the nucleus, cells were stained with DAPI ( $5 \mu \mathrm{M}$ in PBS; Molecular Probes, Inc.) for $5 \mathrm{~min}$ at $25^{\circ} \mathrm{C}$ and washed twice with PBS for $5 \mathrm{~min}$. To visualize the endoplasmic reticulum, cells were 
incubated with $2 \mu \mathrm{M} 3,3^{\prime}$ dihexyloxacarbocyanide iodide (DiOC 6 (3)) for 5 min (Molecular Probes, Inc.) (Sabnis et al. 1997). Slides were analyzed in a Zeiss LSM 510 confocal microscope (Carl Zeiss, Inc., Thornwood, NY, USA).

\section{Purification of recombinant PATE (rPATE) protein}

Plasmid pRB302 was constructed using a 321 bp PCR product, generated by primers PATE2C: $5^{\prime}$-GAC TGA CTT CAT ATG GGA TCA CTT TCA ATG AGA AAT- $3^{\prime}$ and PATE3N: 5'-TTC CAT TGG AAT TCT AAA GGT CTT CAT TGC ACA G-3' and CR2.1-PATE plasmid (Bera et al. 2002) as a template. The PCR product was subsequently subcloned into a pET-based expression vector pULI7 (Brinkmann et al. 1991) using Ndel and EcoRI restriction sites. Plasmid pRB302 expresses the PATE protein lacking the signal sequence. Escherichia coli BL21 ( $\alpha$ DE3) (Studier \& Moffatt 1986) was transformed with plasmid pRB302. Protein production was induced by isopropyl-beta D-thiogalactoside (IPTG), and PATE accumulated in inclusion bodies. Purification of the protein was performed as described before for immunotoxin purification (Pastan et al. 2003). Briefly, inclusion bodies were solubilized in guanidine hydrochloride solution and reduced with dithioerythritol. Solubilized protein was refolded by dilution in a refolding buffer containing arginine and glutathione to prevent aggregation and to facilitate redox shuffling respectively. Refolded protein was dialyzed and purified by ion exchange chromatography. Protein concentration was determined by Bio-Rad DC protein assay (Bio-Rad).

\section{Generation of anti-PATE rabbit antibody (SOL-1 pAb)}

The generation of polyclonal anti-PATE rabbit antibody (named SOL-1 pAb) was performed by immunization of two rabbits with purified rPATE protein by Spring Valley Laboratories, Inc. (Woodbine, MD, USA) following standard protocols. Two rabbits were primary immunized with $100 \mu \mathrm{g}$ rPATE protein in complete Freund's adjuvant. After primary immunization they were boosted at 21, 42 and 74 days post-immunization with $100 \mu \mathrm{g}$ rPATE protein in incomplete Freund's adjuvant. Rabbits were bled and the development of anti-PATE rabbit antibodies was monitored by Western blot against rPATE protein.

\section{Human sperm collection and tissue samples}

Human semen ejaculates were obtained from normal male donors by masturbation after 3 days of abstinence from ejaculation (samples were designated exempt by the Office of Human Subjects Research, NIH). Ejaculates were allowed to liquefy at $25^{\circ} \mathrm{C}$. Sperms were collected as described by Gupta et al. (1990). Liquified semen was centrifuged at $400 \times \boldsymbol{g}$ for $15 \mathrm{~min}$, washed 3 times in Trisbuffered saline (TBS; $10 \mathrm{mM}$ Tris, $145 \mathrm{mM} \mathrm{NaCl}, \mathrm{pH}$ 7.4) and stored at $-70^{\circ} \mathrm{C}$. Epididymis and seminal vesicle tissues were obtained from the cooperative Human Tissue Network, Southern Division (Philadelphia, PA, USA).

\section{Preparation of cell extracts and Western blot analysis}

Transfected and untransfected 293T cells, seminal vesicle, epididymis and sperm lysates were prepared using NP-40 lysis buffer containing protease inhibitors by incubation on ice for $1 \mathrm{~h}$ (Harlow \& Lane 1999). Frozen tissues were macerated with a cold mortar and pestle and then resuspended in NP-40 lysis buffer (Boehringer). Prostate, testis, brain and spermatic cord total cell lysates were obtained from Clontech. Thirty-five micrograms protein extracts ( $5 \mu \mathrm{g}$ for sperm fractions) were run on a $4-20 \%$ Tris-glycine gel (Bio-Rad) and transferred to a $0.2 \mu \mathrm{m}$ poly (vinylidene difluoride) membrane (Millipore, Billerica, MA, USA) in transfer buffer $(25 \mathrm{mM}$ Tris/192 mM glycine/20\% ( $\mathrm{vol} / \mathrm{vol}$ ) methanol, $\mathrm{pH} 8.3$ ) at $4{ }^{\circ} \mathrm{C}$ overnight. Filters were immunoblotted with anti-PATE SOL-1 pAb (1:1500) followed by goat anti-rabbit HRP conjugated antibodies (1:5000; BioSource, Camarillo, CA, USA). Signals were detected using an ECL chemiluminescence Western blotting kit according to the manufacturer's instructions (Amersham Biosciences).

\section{Association of PATE with sperm}

SOL-1 pAbs raised in rabbit were used to detect the presence of PATE on sperm cells. The secondary fluorescent antibody used was goat anti-rabbit IgG Alexa Fluor 594 (Molecular Probes, Inc.). Fifty microliter aliquots of sperm suspension in PBS were smeared onto Superfrost Plus micro slides (VWR, West Chester, PA, USA). The slides were allowed to air dry in a chemical hood for $10 \mathrm{~min}$. The slides were fixed and stained as described above with the following changes. Sperm smears were fixed with formaldehyde and washed with PBS for 5 min. Slides were blocked and incubated with $100 \mu \mathrm{l} \mathrm{SOL-1}$ pAb (1:250) at $4{ }^{\circ} \mathrm{C}$ overnight in a humid chamber. After primary antibody, slides were washed with PBS and secondary antibody was applied in $100 \mu \mathrm{l}(1: 250$ dilution of $1 \mathrm{mg} / \mathrm{ml})$ and incubated for $1 \mathrm{~h}$ at $25^{\circ} \mathrm{C}$ in a humid chamber in the dark. After secondary antibody, slides were washed and Anti-Fade was applied according to the manufacturer's instructions (Molecular Probes, Inc.). A coverslip was placed on the sperm smear and slides were placed in a slide box and left to dry overnight at $4{ }^{\circ} \mathrm{C}$ wrapped with foil. Slides were analyzed in a Zeiss LSM 510 confocal microscope (Carl Zeiss, Inc.).

\section{Results}

\section{PATE mRNA is expressed in the accessory glands of the male genital tract}

The PATE gene was identified by a functional genomic approach (Bera et al. 2002). Of many tissues examined, PATE mRNA expression was found to be limited to the prostate and testis by multiple tissue dot-blot, PCR on cDNAs from 24 different human tissues and Northern blot analyses (Bera et al. 2002). This limited tissue expression 
suggests that PATE expression is restricted to the male genital tract. To determine if PATE is expressed in the accessory glands of the male genital tract, RT-PCR was performed using total RNA from prostate, testis, epididymis and seminal vesicle. As previously described, PATE mRNA was detected in the prostate and testis. PATE mRNA was also detected in the epididymis and the seminal vesicle (Fig. 1A). As expected, no PCR products were obtained in the water control. These data indicate that the RT-PCR products are specific.

In the normal prostate, PATE mRNA was restricted to the epithelial cells (Bera et al. 2002). To determine the cell types in the testis that express PATE mRNA, in situ hybridization was used with biotin-labeled PATE cDNA as a probe as described in Materials and Methods. As shown in Fig. 1B, PATE mRNA is expressed in spermatogonia. CD22 and U6 probes were used as negative and positive controls respectively. As expected, in situ hybridization with CD22 showed no signal and the U6 probe gave a strong signal confirming the specificity of the in situ hybridization (Fig. 1B). These data suggest that PATE is made in spermatogonia of the testis.

\section{The PATE gene encodes a secreted protein}

The PATE gene encodes a $14-\mathrm{kDa}$ protein based on the predicted amino acid sequence from cloned cDNA (Bera et al. 2002). Amino acid sequence analysis of the predicted PATE protein revealed the presence of a signal sequence with a possible cleavage site between residues G21 and S22 (Fig. 2A). To determine the size of PATE made in mammalian cells and also if PATE is a secreted protein, 293T cells were transiently transfected with plasmid pcDNA3-PATE-myc-His expressing PATE protein with a myc-His epitope tag at the carboxy terminus. PATE-mycHis protein was detected by Western blot in both the total cell lysate and in the culture media (Fig. 2B). To rule out the possibility that the presence of PATE in the medium could be accounted for by cell breakage and release of cellular proteins into the medium we determined if actin was present in the medium. Actin could easily be immunoprecipitated from the total cell lysates of the 293T and 293T/PATE-myc-His transfected cells. However, actin was not detected in the culture media indicating extensive cell breakage did not occur (Fig. 2B).

All the proteins that transit the secretory pathway are translated initially on ribosomes bound to the endoplasmic reticulum (ER) (Blázquez \& Shennan 2000), secreted into the ER and transported to the cell surface. To determine the intracellular localization of PATE protein, 293T cells were transfected with a PATE-myc-His plasmid. After $48 \mathrm{~h}$, the cells were fixed, washed and immunostained with anti-myc mAb, DAPI (nucleus) and $\mathrm{DiOC}_{6}$ (3) (ER). Stained cells were analyzed under the confocal microscope. As shown in Fig. 3, the PATE myc-His protein exhibited the same staining pattern as the ER marker, $\mathrm{DiOC}_{6}(3)$. These data indicate that PATE is synthesized in the ER. Taken together, we conclude that PATE is a secreted protein.

\section{Purification of PATE protein and generation of polyclonal anti-PATE antibodies}

To determine the location of native PATE protein we produced antibodies to PATE. To do this the PATE protein was produced in E. coli. Protein expression on E. coli BL21 was induced with $0.1 \mathrm{mM}$ IPTG (Fig. 4, lane 2). A protein of approximately 12-kDa PATE protein (without signal sequence) was solubilized and purified to near homogeneity from inclusion bodies (Fig. 4, lanes 3 and 4 respectively). Rabbit anti-PATE antibodies were produced as described in Materials and Methods. The protein was then solubilized, purified (lane 4) and used to produce antibodies. To determine Western blot conditions and the minimum amount of rPATE that can be detected by SOL-1 pAb, Western blots were performed using different dilutions of the SOL-1 pAb and different concentrations of rPATE. The SOL-1 pAb could detect as little as $0.05 \mathrm{ng}$ PATE (Fig. 5, lane 5). To determine if the SOL-1 pAb can detect PATE protein expressed in mammalian cells, 293T cells were transfected with pAAS-PATE (a 412 bp HindIII, EcoRV PATE cDNA fragment cloned into HindIII and Stul sites of $\mathrm{pNLX}_{2}$ plasmid), total cell lysates were prepared and the protein analyzed by PAGE gel. Immunoblotting using SOL-1 pAb detected PATE protein in the total cell lysate of 293T cells transfected with pAAS-PATE (Fig. 5, lane 2). As expected, protein was not observed in the 293T untransfected total cell lysate (Fig. 5, lane 1). We conclude that SOL-1 pAb posseses a high affinity for rPATE and can be used to detect PATE protein in mammalian cells.

\section{The PATE protein is a sperm-associated protein}

Because PATE mRNA was expressed in the prostate, testis and other accessory glands of the male genital tract by RTPCR (Fig. 1A) we tried to detect the presence of PATE protein in total cell lysates from these tissues. Thirty-five micrograms brain, prostate, testis, spermatic cord and seminal vesicle protein were separated in a $4-20 \%$ Tris$\mathrm{HCl}$ PAGE gel, transferred to PVDF membranes and immunoblotted with PATE SOL-1 pAb. As expected, PATE protein was not detected in the brain tissue. However, no PATE protein bands were detected in the prostate, testis, spermatic and seminal vesicle (data not shown). The lack of PATE protein detection in the total cell lysates of the prostate, testis, epididymis and seminal vesicle could be due to the fact that gene expression in these tissues is highly regionalized and as a consequence the protein signal is hard to detect by Western blot in the whole tissue.

Because our hypothesis was that PATE was a secreted protein that interacted with sperm and helped promote its development or assisted its function, we next tried to detect PATE in sperm where it might be concentrated. To do this human semen was left to liquefy and then 

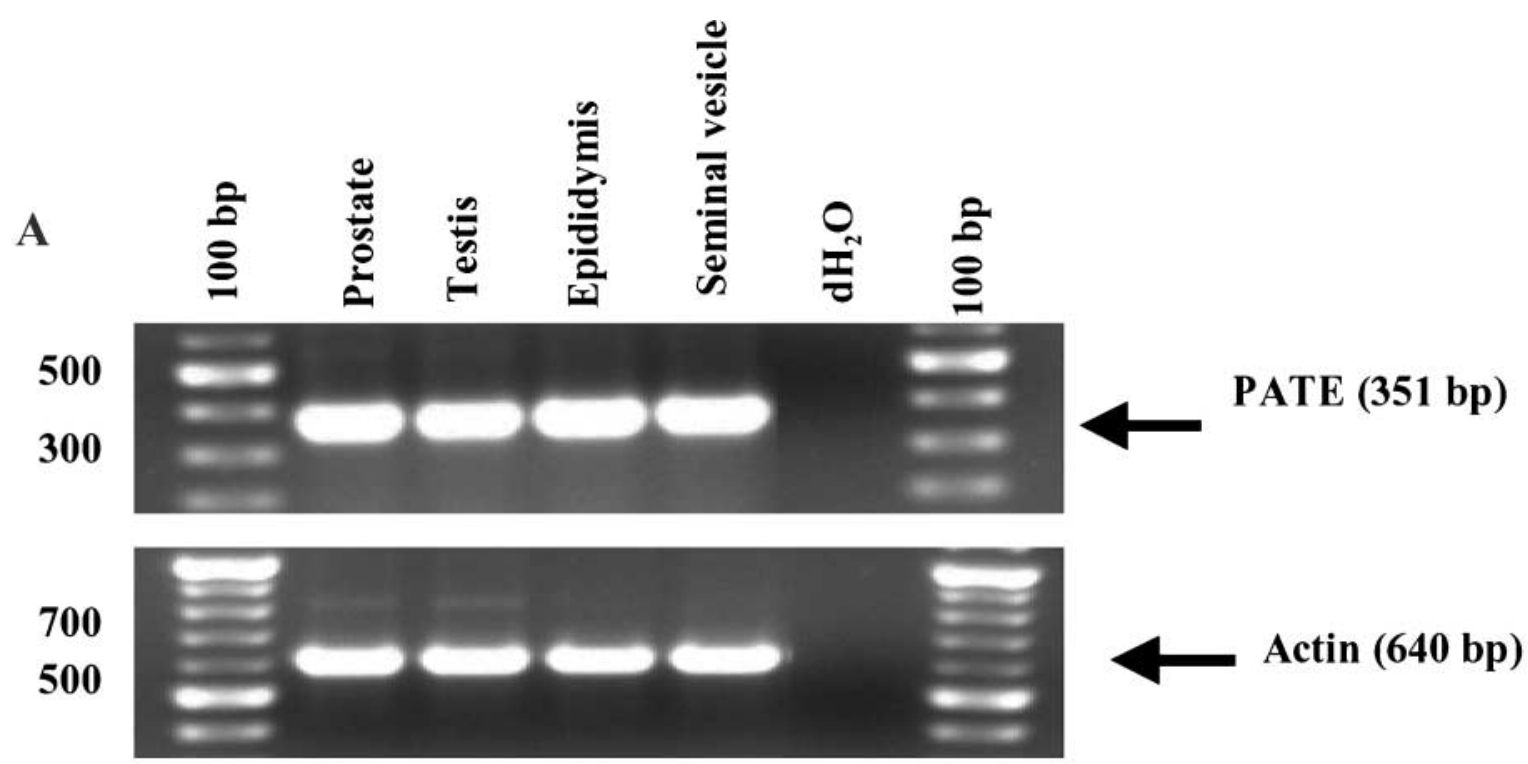

B

H/E
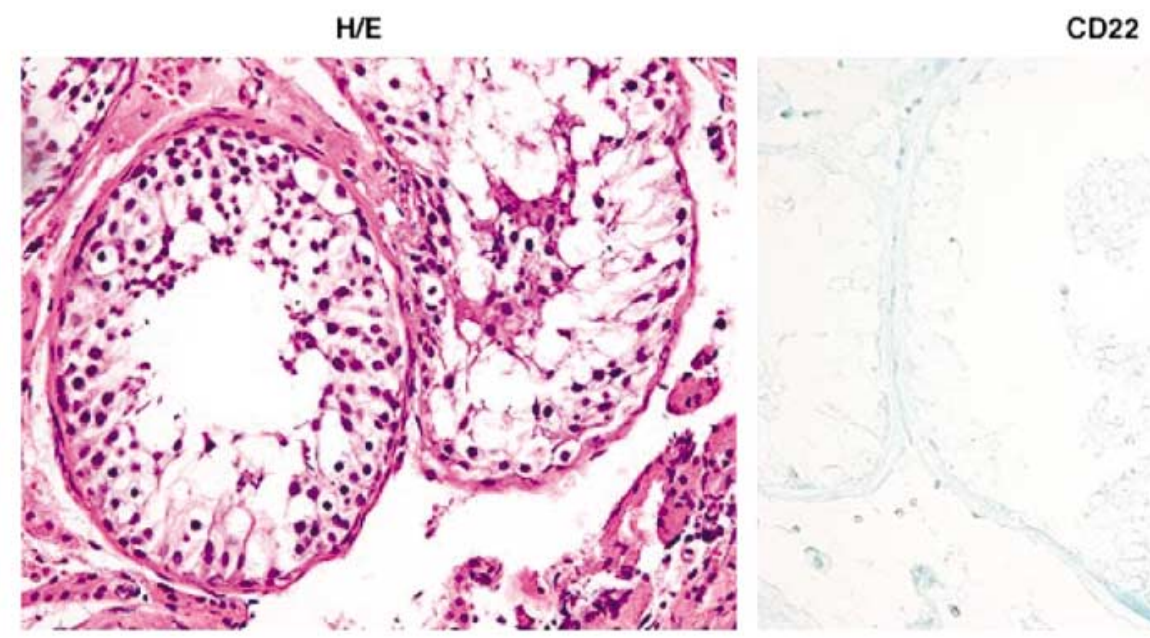

U6

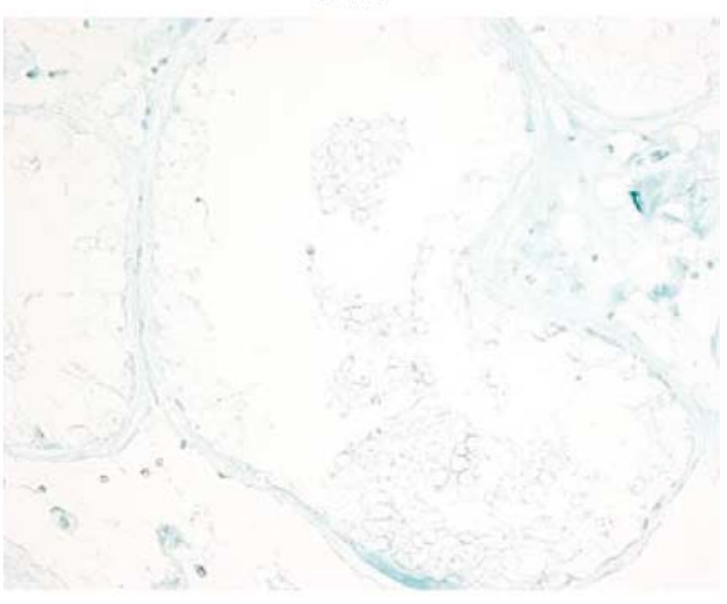

PATE

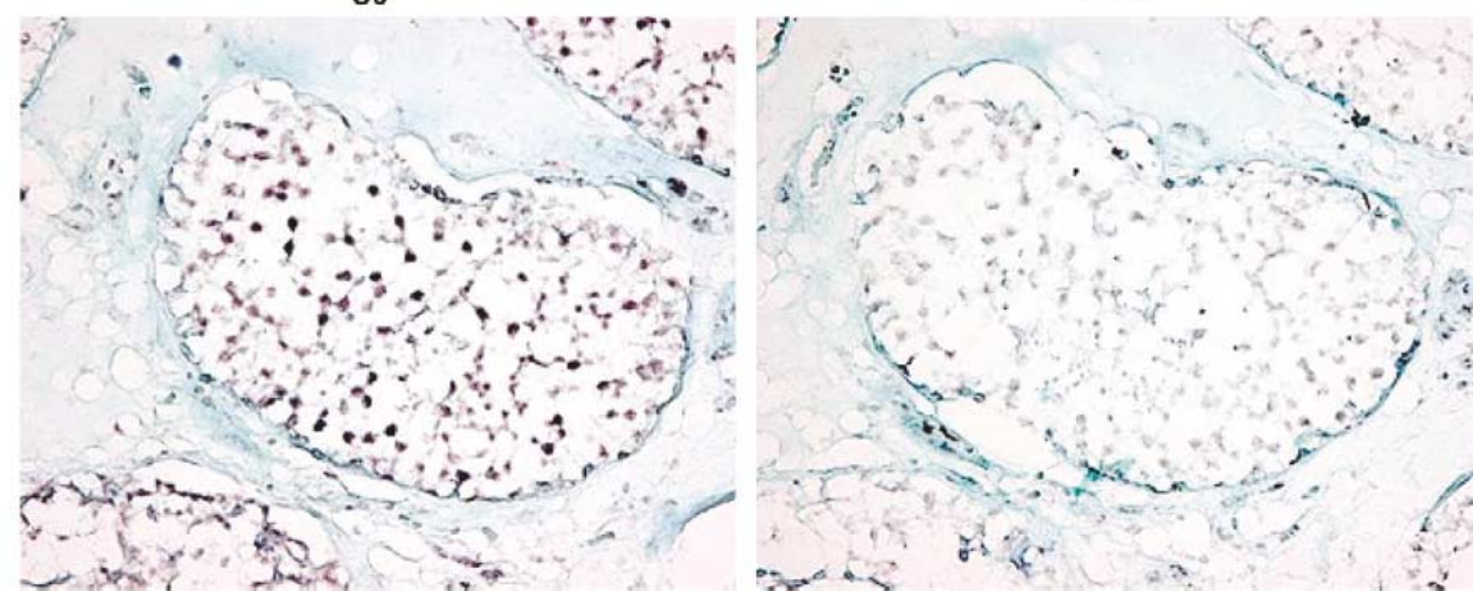

Figure 1 PATE mRNA expression in accessory glands of the male genital tract. (A) RT-PCR analysis of PATE mRNA expression was performed with specific PATE primers (top) or actin primers (bottom) with cDNAs derived from each representative tissue. RT-PCRs performed without templates are indicated as $\mathrm{dH}_{2} \mathrm{O}$. PCR products were separated on a $1 \%$ agarose gel and visualized by ethidium bromide staining. (B) In situ localization of PATE mRNA in the testis. Testis tissue sections were stained with hematoxylin/eosin $(\mathrm{H} / \mathrm{E})$ to show general morphology or probed with plasmid Bluescript containing CD22 (negative control), U6 (positive control) or PATE cDNA. 


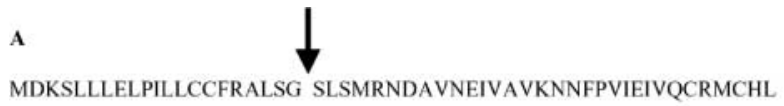

QFPGEKCSRGRGICTATTEEACMVGRMFKRDGNPWLTFMGCLKNCADVKGIRW SVYLVNFRCCRSHDLCNEDL

B

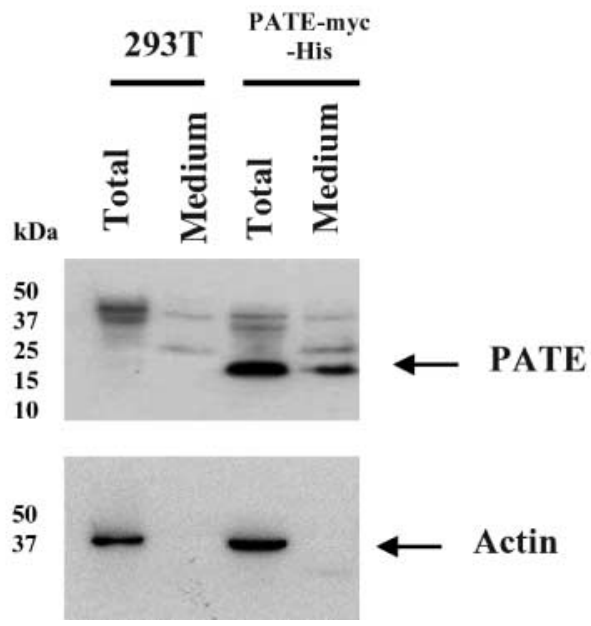

Figure 2 PATE is a secreted protein. (A) Amino acid sequence encoded by the cloned PATE cDNA. The putative cleavage site and phospholipase $\mathrm{A}_{2}$ motif are indicated by arrows and bold characters respectively. Underlined is a histidine residue thought to be critical for phospholipase activity. (B) Secretion of PATE. 293T cells were transfected with pcDNA3-PATE-myc-His. Forty-eight hours later PATE-myc-His or actin proteins were immunoprecipitated with antimyc $\mathrm{mAb}$ or anti-actin $\mathrm{pAb}$ from the culture medium and from the cell lysates.

centrifuged to separate the sperm from the seminal fluid as described in Materials and Methods. Then the sperm was lysed with NP-40 lysis buffer and centrifuged to separate the soluble (supernatant) from the non-soluble material (pellet). Five micrograms of each sperm fraction were analyzed in 4-20\% PAGE gel followed by PVDF membrane transfer and immunoblotting with SOL-1 pAb. PATE protein was detected in the sperm supernatant fraction (Fig. 5, lane 3). The 12-kDa PATE was completely absent in the sperm pellet fraction (Fig. 5, lane 4). Although protein bands were detected in the seminal fluid fraction of ejaculated spermatozoa none of the bands exhibited the expected molecular weight of the PATE protein (data not shown). However, the reactivity of proteins greater than 12-kDa (the molecular mass of secreted PATE) indicates that PATE may associate with other proteins present in the seminal fluid or in the sperm. Also PATE may associate with itself forming aggregates leading to the ladder of band sizes in the Western blot.

To confirm that PATE protein is associated with human sperm and to determine its location on sperm, confocal microscopy was performed after immunostaining PATE with SOL-1 pAb (1:250 dilution). Association of PATE with sperm could be observed and was localized to a band-like pattern lying in the sperm head (Fig. 6E and $\mathrm{H}$ ). As a negative control, rabbit pre-immune sera were used at the same dilution. As expected, no PATE protein was detected using the pre-immune rabbit sera (Fig. 6A and D).

\section{Discussion}

In this paper we have demonstrated that several accessory tissues of the male reproductive system contain PATE mRNA, but that PATE protein can only be detected on human sperm where it is located in an unusual banding pattern. We found by RT-PCR that PATE mRNA was also highly expressed in the epididymis and seminal vesicles (Fig. 1A). This finding confirms that PATE is expressed exclusively in the male genital tract. In situ hybridization of the testis indicated that PATE mRNA is predominantly expressed in the spermatogonia leading to the hypothesis that the PATE protein may be involved in the development and/or is associated with the sperm.

The wide expression of PATE mRNA in the male genital tract may suggest an important role of this gene in cell development. Prosaposin is an example of this expression pattern in multiple tissues of the male genital tract. This gene is a multifunctional locus found in human (Leonova et al. 1996), mouse (Sun et al. 1994, Morales et al. 1998) and rat (Morales et al. 1996) and encodes four glycoprotein activators or saponins expressed in several tissues including the male genital tract (Kishimoto et al. 1992). Targeted disruption of this widely expressed gene in mice leads to a decrease in testis size with reduced spermiogenesis and involution of the prostate, seminal vesicle and epididymis (Morales et al. 2000).

Computer analysis of the predicted amino acid sequence of the PATE protein revealed a putative cleavage site between residues $\mathrm{G} 21$ and S22. Immunoprecipitation experiments demonstrated that PATE-myc-His protein was secreted to the culture media of 293T transiently transfected cells as shown in the Western blot using anti-myc $\mathrm{mAb}$ (Fig. 2B). Moreover, the subcellular localization of PATE-myc-His protein in the ER of the transiently transfected 293T cells by confocal microscopy confirms that PATE is a secreted protein that is processed and transported in the secretory pathway.

SOL-1 pAb, a polyclonal antibody raised in rabbits, was generated and therefore used to detect PATE protein in commercially and laboratory-made protein lysates of prostate, testis, spermatic cord and seminal vesicle. Western blot analysis did not show PATE protein in these tissues even though PATE mRNA is abundantly expressed. This observation suggests that PATE as a secreted protein is rapidly made, processed and secreted out of these tissues. However, PATE protein was detected by Western blot in the supernatant fraction of the sperm. The latter finding together with the fact that PATE mRNA was present in specialized cells of the testis involved in sperm development led us to hypothesize that PATE is a novel spermassociated protein (Fig. 1B). Furthermore, BLASTP analysis of the PATE amino acid sequence against the National Center for Biotechnology Information's 'non-redundant' 


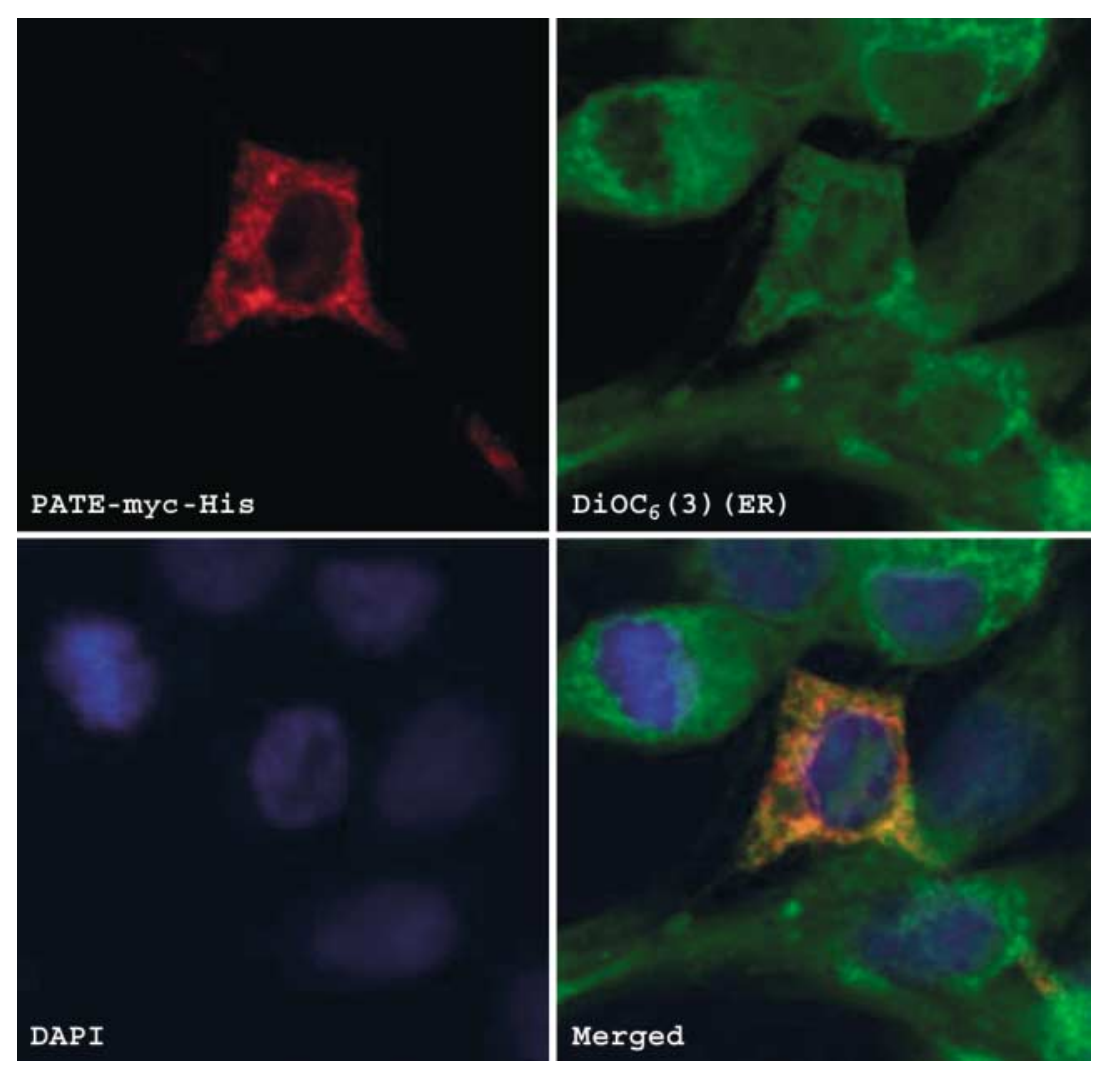

Figure 3 PATE subcellular localization. 293T cells transfected with PATE-myc-His plasmid were grown on cover slips. Cells were washed, fixed and stained as described in Materials and Methods. PATE-myc-His protein was detected using anti-myc mAb. DiOC 6 (3) and DAPI were used to stain the ER and the nucleus respectively.

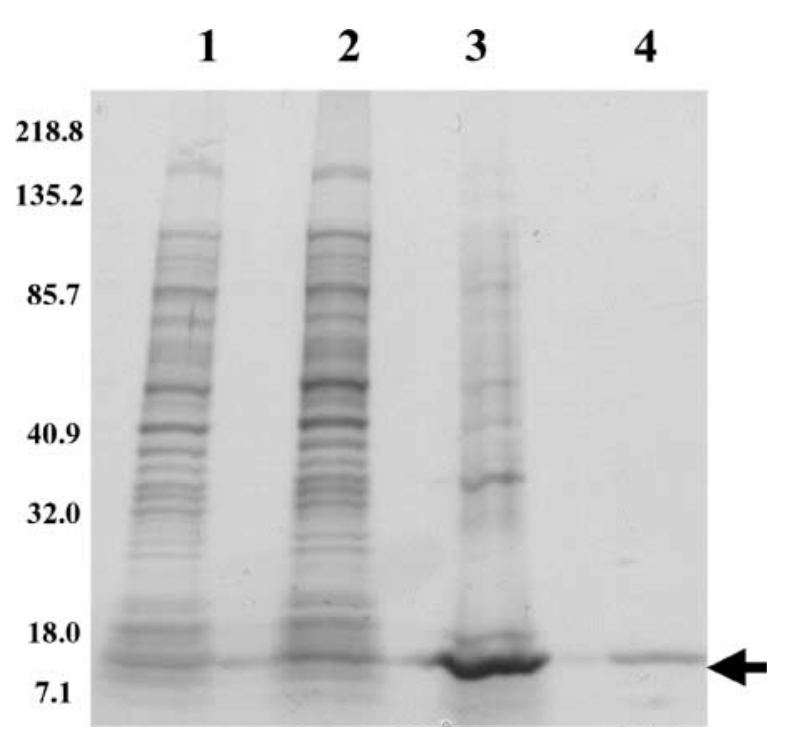

Figure 4 Purification of rPATE protein. rPATE protein expression was induced on E. coli by IPTG, concentrated in inclusion bodies and purified as described in Materials and Methods. Lanes 1 and 2 correspond to un-induced and IPTG-induced rPATE expression in E. coli respectively ( $10 \mu \mathrm{g}$ total protein); lane 3 , inclusion bodies $(5 \mu \mathrm{g})$; lane 4, purified PATE $(1.5 \mu \mathrm{g})$. Gel was stained with Gel Code Blue following the manufacturer's instructions (Pierce, Rockford, IL, USA). Arrow indicates PATE protein.

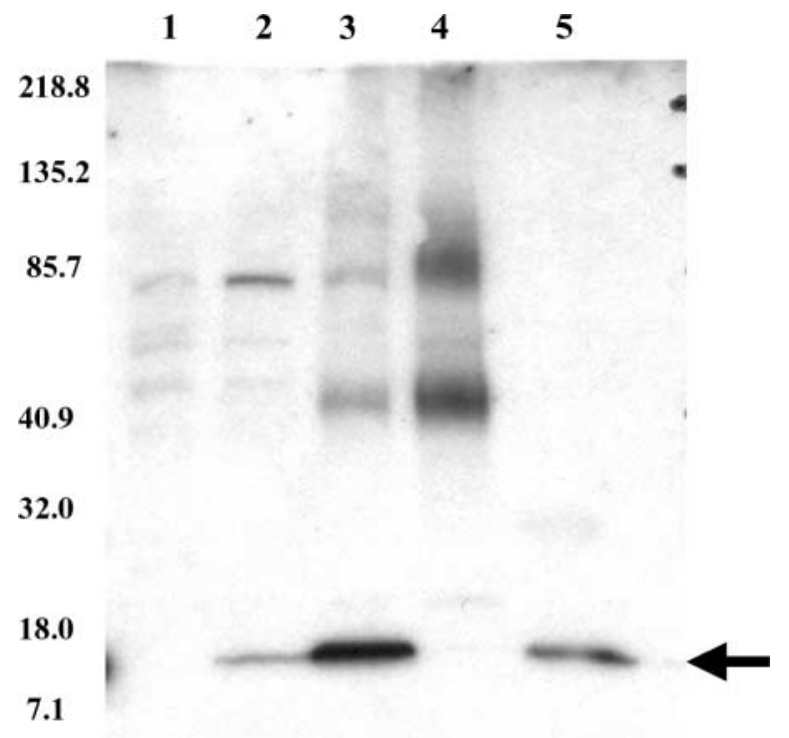

Figure 5 Detection of PATE in human sperm. Spermatozoa were isolated and treated with NP-40 lysis buffer. Proteins were resolved in a 4-20\% PAGE gel, transferred overnight to a PVDF membrane and immunoblotted with SOL-1 pAb. Lane 1, 293T (untransfected cells, $35 \mu \mathrm{g})$; lane 2, 293T/PATE transfected cells (35 $\mu \mathrm{g})$; lane 3, sperm supernatant $(5 \mu \mathrm{g})$; lane 4 , sperm pellet $(5 \mu \mathrm{g})$; lane 5 , rPATE $(0.05 \mathrm{ng})$. Arrow indicates PATE protein. 

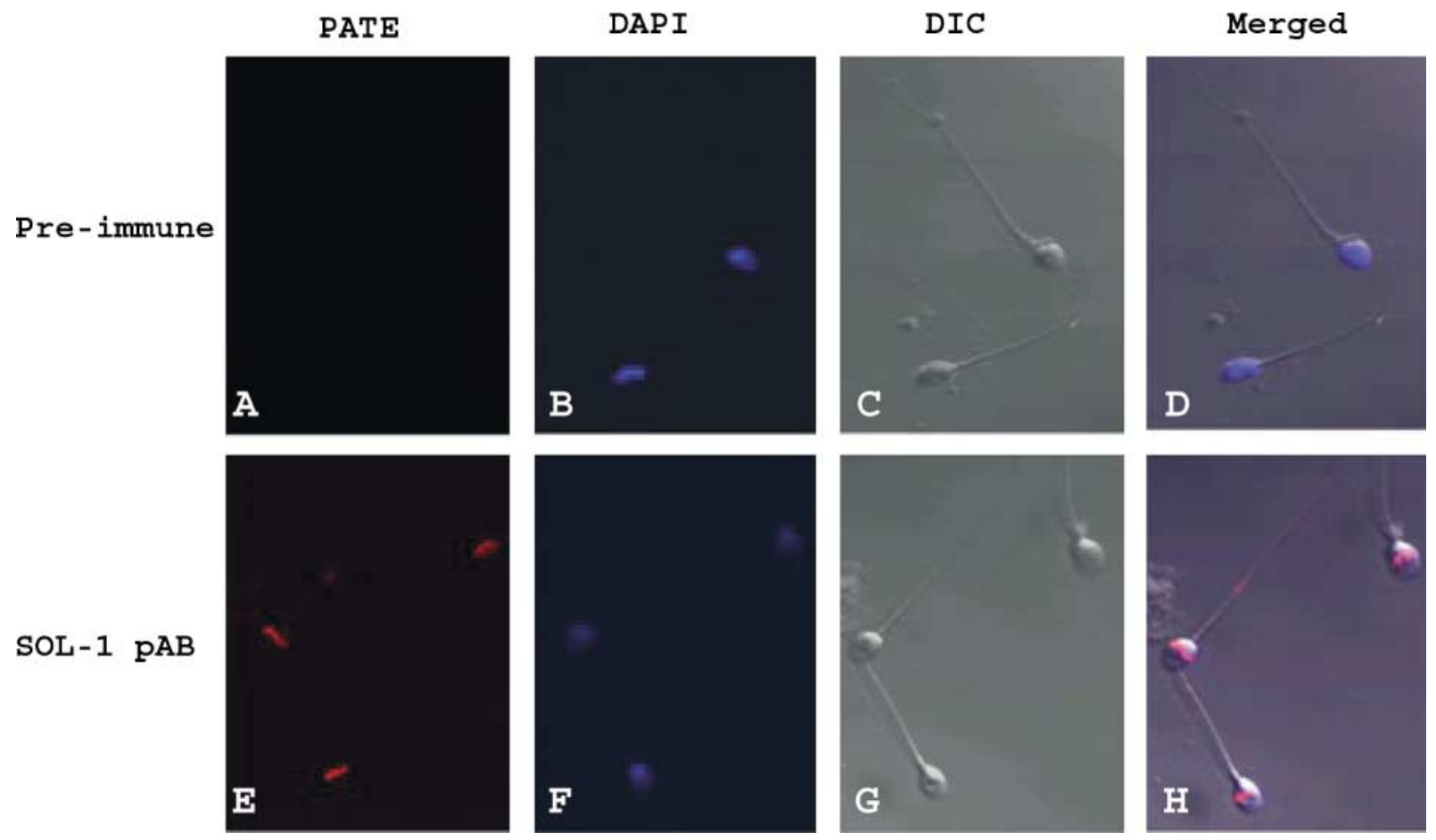

Figure 6 Localization of PATE associated with human sperm. Human spermatozoa were collected by centrifugation. Sperm smears were prepared in Superfrost Plus slides. Cells were washed, fixed and stained as described in Materials and Methods. PATE protein was detected using PATE SOL-1 pAb (1:250 dilution). Pre-immune rabbit serum was used as a negative control. (A) Pre-immune; (B and F) DAPI stain; (C and G) differential interference contrast microscopy (DIC); (E) rabbit anti-PATE (SOL-1); (D and H) merged images of A, B and E, F respectively. Magnification $\times 630$.

database (http://www.ncbi.nlm.nih.gov/blast/) resulted in similarities to the acrosomal vesicle protein SP-10. The aligned part of the SP-10 protein belongs to a snake toxin family of proteins according to the sequence-based protein classification database, Pfam. This protein may play a role in sperm-zona binding and penetration (Foster et al. 1994).

Confocal microscopy of immunostained sperm smears demonstrated that PATE protein is indeed associated with the human sperm. PATE protein was localized to a bandlike pattern in the sperm head (Fig. 6E and H). Other sperm-associated proteins that exhibit this band-like pattern are cystatin-related epididymal spermatogenic and equatorial sperm proteins (Wassler et al. 2002, Wolkowicz et al. 2003). In the case of these two proteins the characteristic band-like pattern is located between the principal and the equatorial segments of the sperm head. The equatorial segment is formed in the late spermatid stage and it is maintained until it is incorporated into the oocyte (Toshimori 1998). A role for the sperm equatorial segment during fertilization has been proposed by Ellis et al. (2002). After the sperm penetrates the egg the equatorial segment is believed to initiate sperm-egg adhesion. This adhesion step is mediated by the protein fertilin (Evans et al. 1997a, b). The fusion capacity of the equatorial segment has been demonstrated experimentally by fusion with liposomes (Arts et al. 1997). This finding suggests that PATE protein probably plays a role in mammalian fertilization (Wassarman et al. 2001).

The predicted amino acid sequence of the PATE protein exhibits a phospholipase $A_{2}$ motif (Fig. 2A) and fold-recognition programs group PATE protein as a member of a superfamily of proteins that includes the snake venom toxin, neurotoxins and cardiotoxins (Bera et al. 2002). The presence of the phospholipase motif and the low molecular weight of the protein suggest that PATE could exhibit phospholipase activity. This is important because phospholipases have been shown to influence a wide range of cellular activities such as inflammation (Murakami et al. 1997), proliferation (Anderson et al. 1997), apoptosis (Zhang et al. 1999, Taketo \& Sonoshita 2002), carcinogenesis (Graff et al. 2001, Jiang et al. 2002), and protection against microbial infection (Buckland et al. 2000). The phospholipase activity can be an important property of the PATE protein given that the membranes of the mammalian spermatozoa undergo extensive plasma membrane remodeling during maturation in the epididymal duct (Christova et al. 2002). Riffo and Parraga (1997) demonstrated through in vitro experiments that antibodies against phospholipase $\mathrm{A}_{2}$ inibit sperm-egg fusion.

In conclusion, PATE is a highly expressed gene in the male genital tract that encodes a novel secreted spermassociated protein that may play crucial roles during sperm development, maturation and fertilization. 


\section{Acknowledgements}

We thank Susan Garfield for technical assistance in confocal microscopy, the members of the Gene Discovery Group for their valuable comments during this study and Anna Mazzuca for editorial assistance. The authors declare no conflict of interest that would affect the impartiality of this scientific work.

\section{References}

Al-Somai N, Vishwanath R, Shannon P \& Molan PC 1994 Low molecular weight components in bovine semen diffusate and their effects on motility of bull sperm. Reproduction, Fertility and Development 6 165-171.

Anderson KM, Roshak A, Winkler JD, McCord M \& Marshall LA 1997 Cytosolic 85-kDa phospholipase A2-mediated release of arachidonic acid is critical for proliferation of vascular smooth muscle cells. Journal of Biological Chemistry 272 30504-30511.

Arts EG, Wijchman JG, Jager S \& Hoekstra D 1997 Protein involvement in the fusion between the equatorial segment of acrosomereacted human spermatozoa and liposomes. Biochemical Journal $325191-198$.

Bedford JM 1975 Maturation, transport and fate of spermatozoa in the epididymis. In Handboook of Psysiology, vol. 7, Endocrinology, vol. 5, pp 303-317. Eds DW Hamilton and RO Greep. Washington: American Physiology Society.

Bera TK, Maitra R, lavarone C, Salvatore G, Kumar V, Vincent JJ, Sathyanarayana BK, Duray P, Lee BK \& Pastan I 2002 PATE, a gene expressed in prostate cancer, normal prostate, and testis, identified by a functional genomic approach. PNAS 99 3058-3063.

Blázquez M \& Shennan KIJ 2000 Basic mechanisms of secretion: sorting into the regulated secretory pathway. Biochemistry and Cell Biology 78 181-191.

Brinkmann U, Pai LH, FitzGerald DJ, Willingham M \& Pastan I 1991 B3(Fv)-PE38KDEL, a single-chain immunotoxin that causes complete regression of a human carcinoma in mice. PNAS $\mathbf{8 8}$ 8616-8620.

Buckland AG, Heeley EL \& Wilton DC 2000 Bacterial cell membrane hydrolysis by secreted phospholipases $\mathrm{A}(2)$ : a major physiological role of human group Ila $\operatorname{SPLA}(2)$ involving both bacterial cell wall penetration and interfacial catalysis. Biochimica et Biophysica Acta 1484 195-206.

Christova Y, James PS, Cooper TG \& Jones R 2002 Lipid diffusion in the plasma membrane of mouse spermatozoa: changes during epididymal maturation, effects of $\mathrm{pH}$, osmotic pressure, and knockout of the c-ros gene. Journal of Andrology 23 384-392.

Collard MW \& Griswold MD 1987 Biosynthesis and molecular cloning of sulfated glycoprotein 2 secreted by rat Sertoli cells. Biochemistry 26 3297-3303.

Cornwall GA, Orgebin-Crist MC \& Hann SR 1992 The CRES gene: a unique testis-regulated gene related to the cystatin family is highly restricted in its expression to the proximal region of the mouse epididymis. Molecular Endocrinology 6 1653-1664.

Ducheux J-L, Gatti JL \& Dacheux F 2003 Contribution of epididymal secretory proteins for spermatozoa maturation. Microscopy Research and Technique 61 7-17.

Ellis DJ, Shadan S, James PS, Henderson RM, Michael Edwardson JM, Hutchings A \& Ones R 2002 Post-testicular development of a novel membrane substructure within the equatorial segment of ram, bull, boar, and goat spermatozoa as viewed by atomic force microscopy. Journal of Structural Biology 138 187-198.

Evans JP, Kopf GS \& Schultz RM 1997 a Characterization of the binding of recombinant mouse sperm fertilin beta subunit to mouse eggs: evidence for adhesive activity via an egg beta1 integrinmediated interaction. Developmental Biology 187 79-93.
Evans JP, Schultz RM \& Kopf GS 1997b Characterization of the binding of recombinant mouse sperm fertilin alpha subunit to mouse eggs: evidence for function as a cell adhesion molecule in spermegg binding. Developmental Biology 187 94-106.

Foster JA, Klotz KL, Flickinger CJ, Thomas TS, Wright RM, Castillo JR \& Herr JC 1994 Human SP-10: acrosomal distribution, processing, and fate after the acrosome reaction. Biology of Reproduction $\mathbf{5 1} 1222-1231$

Graff JR, Konicek BW, Deddens JA, Chedid M, Hurst BM, Colligan B, Neubauer BL, Carter HW \& Carter JH 2001 Expression of group Ila secretory phospholipase A2 increases with prostate tumor grade. Clinical Cancer Research 7 3857-3861.

Griswold MD, Roberts K \& Bishop P 1986 Purification and characterization of a sulfated glycoprotein secreted by Sertoli cells. Biochemistry 25 7265-7270.

Gupta SK, Fulgham DL \& Alexander NJ 1990 Sperm preparation affects reactivity of monoclonal antibodies. Journal of Reproductive Immunology 18 187-197.

Harlow E \& Lane D 1999 In Using Antibodies: A Laboratory Manual, pp 223-264. New York: Cold Spring Harbor Laboratory.

Hinton BT \& Palladino MA 1995 Epididymal epithelium: its contribution to the formation of a luminal fluid microenvironment. Microscopy Research and Technique 30 67-81.

Hinton BT, Palladino MA, Rudolph D, Lan ZJ \& Labus JC 1996 The role of the epididymis in the protection of spermatozoa. Current Topics in Developmental Biology 33 61-102.

Iwamoto $\mathrm{T}$, Tsang A, Luterman $\mathrm{M}$, Dickson J, de Lamirande $\mathrm{E}$, Okuno M, Mohri H \& Gagnon C 1992 Purification and characterization of a sperm motility-dynein ATPase inhibitor from boar seminal plasma. Molecular Reproduction and Development 31 55-62.

Jeng H, Liu KM \& Chang WC 1993 Purification and characterization of reversible sperm motility inhibitors from porcine seminal plasma. Biochemical and Biophysical Research Communications 191 435-440.

Jiang J, Neubauer BL, Graff JR, Chedid M, Thomas JE, Roehm NW, Zhang S, Eckert GJ, Koch MO, Eble JN \& Cheng L 2002 Expression of group IIA secretory phospholipase A2 is elevated in prostatic intraepithelial neoplasia and adenocarcinoma. American Journal of Pathology 160 667-671.

Kirchhoff C, Osterhoff C, Pera I \& Schroter S 1998 Function of human epididymal proteins in sperm maturation. Andrologia $\mathbf{3 0}$ 225-232.

Kishimoto Y, Hiraiwa M \& O'Brien JS 1992 Saposins: structure, function, distribution, and molecular genetics. Journal of Lipid Research 33 1255-1267.

Kumar V \& Collins FH 1994 A technique for nucleic acid in situ hybridization to polytene chromosomes of mosquitoes in the Anopheles gambiae complex. Insect Molecular Biology 3 41-47.

Leonova T, Qi X, Bencosme A, Ponce E, Sun Y \& Grabowski GA 1996 Proteolytic processing patterns of prosaposin in insect and mammalian cells. Journal of Biological Chemistry 271 $17312-17320$.

Luo CW, Lin HJ \& Chen YH 2001 A novel heat-labile phospholipidbinding protein, SVS VII, in mouse seminal vesicle as a sperm motility enhancer. Journal of Biological Chemistry 276 6913-6921.

Morales CR, El-Alfy M, Zhao Q \& Igdoura SA 1996 Expression and tissue distribution of rat sulfated glycoprotein-1 (prosaposin). Journal of Histochemistry and Cytochemistry 44 327-337.

Morales CR, Hay N, El-Alfy M \& Zhao Q 1998 Distribution of mouse sulfated glycoprotein-1 (prosaposin) in the testis and other tissues. Journal of Andrology 19 156-164.

Morales CR, Zhao Q, El-Alfy M \& Suzuki K 2000 Targeted disruption of the mouse posaposin gene affects the development of the prostate gland and other male reproductive organs. Andrologia 21 $765-775$. 
Murakami M, Nakatani Y, Atsumi G, Inoue K \& Kudo I 1997 Regulatory functions of phospholipase A2. Critical Reviews in Immunology 17 225-283.

NagDas SK, Winfrey VP \& Olson GE 2000 Identification of a hamster epididymal region-specific secretory glycoprotein that binds nonviable spermatozoa. Biology of Reproduction 63 1428-1436.

Nichol R, Hunter RH, de Lamirande E, Gagnon C \& Cooke GM 1997 Motility of spermatozoa in hydrosalpingeal and follicular fluid of pigs. Journal of Reproduction and Fertility 110 79-86.

Olsson P, Bera TK, Essand M, Kumar V, Duray P, Vincent J, Lee B \& Pastan I 2001 GDEP a new gene differentially expressed in normal prostate and prostate cancer. Prostate 48 231-241.

Orgebin-Crist MC 1969 Studies on the function of the epididymis. Biology of Reproduction 1 (Suppl 1) 155-175.

Pang SF, Chow PH \& Wong TM 1979 The role of the seminal vesicles, coagulating glands and prostate glands on the fertility and fecundity of mice. Journal of Reproduction and Fertility $\mathbf{5 6}$ 129-132.

Pastan I, Beers R \& Bera TK 2003 Recombinant immunotoxins in the treatment of cancer. Methods in Molecular Biology 248 503-518.

Peitz B 1988 Effects of seminal vesicle fluid components on sperm motility in the house mouse. Journal of Reproduction and Fertility 83 169-176.

Peitz B \& Olds-Clarke P 1986 Effects of seminal vesicle removal on fertility and uterine sperm motility in the house mouse. Biology of Reproduction 35 608-617.

Riffo MS \& Parrga M 1997 Role of phospholipase A2 in mammalian sperm-egg fusion: development of hamster oolemma fusibility by lysophosphatidylcholine. Journal of Experimental Zoology 279 81-88.

Robaire B \& Viger RS 1995 Regulation of epididymal epithelial cell functions. Biology of Reproduction 52 226-236.

Robert M \& Gagnon C 1996 Purification and characterization of the active precursor of a human sperm motility inhibitor secreted by the seminal vesicles: identity with semenogelin. Biology of Reproduction 55 813-821.
Sabnis RW, Deligeorgiev TG, Jachak MN \& Dalvi TS $1997 \mathrm{DiOC}_{6}(3)$ : a useful dye for staining the endoplasmic reticulum. Biotechnic and Histochemistry 72 253-258.

Studier FW \& Moffatt BA 1986 Use of bacteriophage T7 RNA polymerase to direct selective high-level expression of cloned genes. Journal of Molecular Biology 189 113-130.

Sun Y, Witte DP \& Grabowski GA 1994 Developmental and tissuespecific expression of prosaposin mRNA in murine tissues. American Journal of Pathology 145 1390-1398.

Sylvester SR, Morales C, Oko R \& Griswold MD 1991 Localization of sulfated glycoprotein-2 (clusterin) on spermatozoa and in the reproductive tract of the male rat. Biology of Reproduction 45 195-207.

Taketo MM \& Sonoshita M 2002 Phospholipase A2 and apoptosis. Biochimica et Biophysica Acta 1585 72-76.

Toshimori K 1998 Maturation of mammalian spermatozoa: modifications of the acrosome and plasma membrane leading to fertilization. Cell Tissue Research 293 177-187.

Wassarman PM, Jovine L \& Litscher ES 2001 A profile of fertilization in mammals. Nature Cell Biology 3 59-64.

Wassler M, Syntin P, Sutton-Walsh HG, Hsia N, Hardy DM \& Cornwall GA 2002 Identification and characterization of cystatinrelated epididymal spermatogenic protein in human spermatozoa: localization in the equatorial segment. Biology of Reproduction 67 795-803.

Wolkowicz MJ, Shetty J, Westbrook A, Klotz K, Jayes F, Mandal A, Flickinger CJ \& Herr JC 2003 Equatorial segment protein defines a discrete acrosomal subcompartment persisting throughout acrosomal biogenesis. Biology of Reproduction 69 735-745.

Zhang Y, Lemasters J \& Herman B 1999 Secretory group IIA phospholipase $A(2)$ generates anti-apoptotic survival signals in kidney fibroblasts. Journal of Biological Chemistry $27427726-27733$.

Received 18 November 2004

First decision 21 December 2004

Revised manuscript received 4 January 2005

Accepted 14 January 2005 